\title{
Technical and Vocational Education and Training (TVET): Tempat Asas Pembinaan Budaya Keselamatan di Malaysia
}

\author{
Rosidi Fahlid Mohd Isa \\ Fakulti Teknikal dan Vokasional, Universiti Pendidikan Sultan Idris, Tanjong Malim, Perak, Malaysia \\ Corresponding author, e-mail: cdfahlid@yahoo.com.my
}

\begin{abstract}
The purpose of this study was to evaluate occupational safety and health practices among students and lecturers of the Technical Education and Vocational Training Institute (TVET) in Malaysia from the point of view of safety practice, implementation level, compliance and cultural level of occupational safety and health practices. The methodology used in this study uses a quantitative approach. The study was carried out in two parts, Part A was about the personal information of the respondents and Part B was the survey using a questionnaire with respondents from several Technical Education and Vocational Training institutes (TVET) such as Vocational College (KV), Industrial Training Institute (ILP) , National Youth Skills Institute (IKBN) and Mara Skills Institute (IKM). Descriptive statistics tests used to describe occupational safety and health practices, levels of occupational safety and health, occupational safety and health compliance and occupational safety and health culture, found that they applied high level of practice, safety implementation. This means that almost all students and faculty agree that compliance with occupational safety and health practices is of utmost importance and practiced. From this culture of safety practices will create a safe work culture, which will indirectly create a safety culture. An organization that provides a safe environment will benefit workers in their work activities
\end{abstract}

Keywords: Safety Culture Practice, Technical and Vocational Education and Training (TVET), Occupational Health.

\section{PENGENALAN}

Dalam arus perkembangan dunia masa kini bagi mewujudkan sebuah negara perindustrian, negara amat memerlukan lebih banyak tenaga kerja yang mahir. Sehubungan dengan itu, untuk melatih dan membentuk tenaga kerja yang diperlukan ke arah negara perindustrian, maka pelajar perlu dilatih supaya mempunyai sikap kerja yang betul dan mempunyai nilai-nilai positif seperti berdisiplin, tekun dan dedikasi. Bagi sebuah negara berindustri yang berteknologi adalah memerlukan tenaga kerja yang berdisiplin, yang dilengkapi dengan asas kemahiran yang lebih luas serta mempunyai budaya dan etika kerja yang positif. Dalam usaha ini, pihak Kementerian Sumber Manusia berhasrat menjadikan Malaysia sebuah negara yang selamat untuk bekerja.

Kerajaan juga turut sedar tentang kepentingan pembangunan sumber tenaga manusia dan tidak boleh ketinggalan dalam meningkatkan lagi keupayaan institusi Pendidikan Teknikal dan Latihan Vokasional TVET untuk terus kekal kompetitif dalam suasana pasaran yang sentiasa berubah. Perkara ini dapat dilihat melalui peningkatan peruntukan dalam Rancangan Malaysia (2010), dari sebanyak RM1.9 bilion dalam Rancangan Malaysia Ketujuh (RMK-7) 1996 hingga 2000 meningkat kepada RM3.8 bilion dalam Rancangan Malaysia Kelapan (RMK-8) 2001 hingga 2005. Di dalam Rancangan Malaysia Kesepuluh (RMK-10) bagi tempoh 2011 hingga 2015 pula memperlihatkan satu perubahan ketara, dengan memberi nafas baru seperti mengarus perdanakan pendidikan TVET di negara ini (Aminuddin, 2011).

Selain menjadi sebuah negara maju dalam indutri, Amalan Keselamatan dan Kesihatan Pekerjaan merupakan satu perkara yang sangat penting serta perlu diberikan perhatian yang khusus. Amalan Keselamatan dan Kesihatan Pekerjaan bukan sahaja ditekan 
kepada diri sendiri, tetapi juga mengenai keselamatan pada alatan atau mesin, keselamatan benda kerja, keselamatan tempat kerja dan keselamatan kepada orang lain. Menurut Roslena (2012) Kesedaran terhadap Amalan Keselamatan dan Kesihatan Pekerjaan perlulah ditanam kepada setiap pelajar dan para pekerja supaya sikap mementingkan keselamatan ini dapat diamalkan semasa membuat kerja amali dan seterusnya diamalkan setelah memasuki alam pekerjaan.

Keselamatan boleh dianggap sebagai suatu kebiasaan atau sebagai satu bentuk sikap yang positif. Ianya tidak akan lahir dengan sendiri kecuali manusia itu sendirilah yang membentuknya sama ada hendak menganggapnya sebagai keutamaan ataupun tidak. Bahari (2006) mendefinisikan keselamatan sebagai keadaan yang selamat dan bebas daripada bahaya, termasuk kecederaan dan risiko, pengetahuan atau kemahiran dalam mengelakkan kemalangan atau penyakit dan kualiti atau keadaan yang tidak membawa risiko. Holt (2005) pula mendefinisikan keselamatan sebagai ketiadaan bahaya, ketiadaan ruang yang membantu mewujudkan suasana bahaya, satu tahap perlindungan dan keadaan yang tidak melibatkan risiko.

Mengamalkan Keselamatan dan kesihatan amat penting bagi mengelakkan berlakunya kemalangan terutamanya di dalam bengkel. Ini kerana di bengkel terdapat pelbagai alatan dan mesin yang berbahaya. Oleh itu, apabila berada di dalam bengkel perlulah menjaga keselamatan dan mengikut peraturan yang telah ditetapkan serta mengikut arahan guru atau pensyarah. Pendidikan keselamatan ini perlu ditekankan sebagai salah satu bahagian yang penting dalam pendidikan di sekolah ataupun Pendidikan Teknikal dan Latihan Vokasional (TVET). Dengan adanya pendidikan tersebut, ia dapat memberi pelajar sedikit pengetahuan dan boleh diaplikasikan di rumah dalam melakukan kerja-kerja yang merbahaya. Isu keselamatan juga merupakan perkara utama yang dititik beratkan oleh mana-mana pihak pengurusan syarikat atau jabatan pentadbiran (Bakar, 2012).

Negotiation can occur when two people meet to reconcile their different solutions to the same problem. They interact, behave in a variety of different ways, try to change the perceptions of each other using various forms of language, and recover from a crisis of mutually exclusive expectations. So that there is a standard solution, one of them gets what they want and part of what they want in return, and agrees to implement an agreed-upon thing (Kenedy, 2016).

Keselamatan dan kesihatan pekerjaan merupakan salah satu aktiviti pengurusan sumber manusia yang penting dan berperanan untuk memberikan perlindungan kepada pekerja daripada dan kemalangan semasa menjalankan kerja (Ab. Aziz \& Intan, 2002).

Pendidikan tentang aspek-aspek keselamatan pekerjaan perlulah bermula di peringkat awal lagi. Ini bermakna ibu bapa haruslah memberikan kesedaran tentang aspek keselamatan kepada anak-anak mereka bermula dari rumah hingga ke pendidikan anakanak, di peringkat persekolahan oleh guru-guru dan seterusnya hingga ke peringkat tinggi pendidikan iaitu di institusi pengajian tinggi (Haron, 2008). Langkah-langkah keselamatan pekerjaan hendaklah diterapkan dalam pembelajaran anak-anak sama ada secara formal atau tidak formal bermula dari rumah ke peringkat sekolah dan seterusnya ke peringkat pengajian tinggi. Perkara ini adalah amat penting bagi mengelakkan kemalangan dan kecederaan daripada berlaku terutama dalam kalangan pelajar-pelajar sekolah dan institusi pengajian tinggi.

Menurut Charles (1998) berpendapat, kemalangan ini boleh berlaku dalam dua keadaan. Dalam keadaan pertama ia terjadi kerana tidak disengajakan setelah semua langkah keselamatan diambil. Dalam keadaan kedua, kemalangan berlaku hasil daripada

Isa, R. F. M. (2019). Technical and Vocational Education and Training (TVET): Tempat Asas Pembinaan Budaya Keselamatan di Malaysia. Journal of Vocational Education Studies, 2(2), 101112. DOI: https://doi.org/10.12928/joves.v2i2.1205. 
kelemahan prosedur pencegahan keselamatan. Keadaan yang kedua ini lebih kerap berlaku dalam konteks kemalangan industri berbanding dengan situasi kemalangan pertama tadi.

Mengikut laporan statistik yang dikeluarkan Pertubuhan Keselamatan Sosial (PERKESO) melalui lamab web rasmi PERKESO, jumlah kemalangan di tempat kerja di Negara ini meningkat dari tahun 2009 hingga 2011 iaitu pada tahun 2009 sebanyak 55,186 kes, tahun 2010 sebanyak 57,639 kes dan tahun 2011 sebanyak 59,897 kes. Hasil pemerhatian punca kemalangan di tempat kerja mengikut ringkasan kes kemalangan dari Jabatan Keselamatan dan Kesihatan Pekerjaan, Kementerian Sumber Manusia (2015) pula, majoriti kes kemalangan pada tahun 2011 hingga tahun 2012 adalah disebabkan tiada prosedur kerja yang selamat.

Jabatan Keselamatan dan Kesihatan Pekerjaan (2015) telah mengeluarkan Statistik Kemalangan Pekerjaan Mengikut Sektor sehingga Disember 2015. Statistik berikut diklasifikasikan kepada kemalangan maut, kemalangan tanpa hilang upaya kekal (THUK), dan kemalangan hilang upaya kekal (HUK). Merujuk Jadual 1, Jadual 2 dan Jadual 3.

Berdasarkan jadual di bawah, industri pembinaan mencatatkan jumlah tertinggi bagi kemalangan jenis maut iaitu sebanyak 88 kes daripada 214 kes keseluruhannya. Bagi kemalangan jenis tanpa hilang upaya kekal, industri pembinaan berada di tahap ketiga tertinggi selepas industri pengilangan dan pertanian, perhutanan dan perikanan. Manakala kemalangan jenis hilang upaya kekal pula, industri pembinaan mencatatkan kedudukan kedua tertinggi selepas industri perngilangan iaitu sebanyak 11 kes daripada 122 kes.

Jadual 1. Kemalangan Mengikut Sektor, Maut Tahun 2015

\begin{tabular}{|c|c|c|c|c|c|c|c|c|c|c|c|c|c|c|}
\hline \multirow{2}{*}{ No } & \multirow{2}{*}{ Sektor } & \multicolumn{12}{|c|}{ Maut } & \multirow[t]{2}{*}{ Jumlah } \\
\hline & & Jan & Feb & Mac & Apr & Mei & Jun & Jul & Ogos & Sep & Okt & Nov & Dis & \\
\hline 1 & Pengilangan & 4 & 0 & 3 & 3 & 2 & 6 & 1 & 2 & 3 & 3 & 15 & 4 & 46 \\
\hline 2 & $\begin{array}{l}\text { Perlombongan } \\
\text { dan Kuari }\end{array}$ & 0 & 0 & 1 & 0 & 0 & 0 & 0 & 0 & 0 & 1 & 1 & 1 & 4 \\
\hline 3 & Pembinaan & 3 & 6 & 8 & 3 & 5 & 8 & 4 & 10 & 3 & 9 & 23 & 6 & 88 \\
\hline 4 & $\begin{array}{l}\text { Pertanian, } \\
\text { Perhutanan dan } \\
\text { Perikanan }\end{array}$ & 1 & 1 & 2 & 2 & 3 & 2 & 6 & 2 & 3 & 1 & 6 & 2 & 31 \\
\hline 5 & Kemudahan & 0 & 3 & 0 & 0 & 0 & 0 & 1 & 0 & 0 & 1 & 0 & 1 & 6 \\
\hline 6 & $\begin{array}{l}\text { Pengangkutan, } \\
\text { Penyimpanan } \\
\text { dan Komunikasi } \\
\text { Perdagangan }\end{array}$ & 9 & 1 & 0 & 0 & 0 & 0 & 1 & 0 & 1 & 2 & 7 & 1 & 22 \\
\hline 7 & $\begin{array}{l}\text { Borong dan } \\
\text { Runcit }\end{array}$ & 0 & 1 & 0 & 1 & 0 & 0 & 0 & 0 & 0 & 1 & 0 & 0 & 3 \\
\hline 8 & $\begin{array}{l}\text { Hotel dan } \\
\text { Restoran } \\
\text { Kewangan, } \\
\text { Insuran, }\end{array}$ & 0 & 0 & 0 & 0 & 0 & 0 & 0 & 0 & 0 & 0 & 0 & 0 & 0 \\
\hline 9 & $\begin{array}{l}\text { Hartanah dan } \\
\text { Perkhidmatan } \\
\text { Perniagaan } \\
\text { Perkhidmatan }\end{array}$ & 0 & 2 & 0 & 0 & 1 & 2 & 0 & 3 & 0 & 0 & 5 & 1 & 14 \\
\hline 10 & $\begin{array}{l}\text { Awam dan pihak } \\
\text { Berkuasa } \\
\text { Berkanun }\end{array}$ & 0 & 0 & 0 & 0 & 0 & 0 & 0 & 0 & 0 & 0 & 0 & 0 & 0 \\
\hline & Jumlah & 17 & 14 & 14 & 9 & 11 & 18 & 13 & 17 & 10 & 18 & 57 & 16 & 214 \\
\hline
\end{tabular}

Isa, R. F. M. (2019). Technical and Vocational Education and Training (TVET): Tempat Asas Pembinaan Budaya Keselamatan di Malaysia. Journal of Vocational Education Studies, 2(2), 101112. DOI: https://doi.org/10.12928/joves.v2i2.1205. 
Jadual 2. Kemalangan Mengikut Sektor, Tanpa Hilang Upaya Kekal ( THUK ) Tahun 2015

\begin{tabular}{|c|c|c|c|c|c|c|c|c|c|c|c|c|c|c|}
\hline \multirow{2}{*}{ No } & \multirow{2}{*}{ Sektor } & \multicolumn{12}{|c|}{ THUK } & \multirow[t]{2}{*}{ Jumlah } \\
\hline & & Jan & Feb & Mac & Apr & Mei & Jun & Jul & Ogos & Sept & Okt & Nov & Dis & \\
\hline 1 & Pengilangan & 182 & 110 & 154 & 147 & 128 & 183 & 205 & 180 & 178 & 181 & 132 & 123 & 1903 \\
\hline 2 & $\begin{array}{l}\text { Perlombongan } \\
\text { dan Kuari }\end{array}$ & 3 & 2 & 8 & 3 & 1 & 0 & 1 & 1 & 5 & 5 & 2 & 1 & 32 \\
\hline 3 & Pembinaan & 10 & 9 & 13 & 11 & 6 & 26 & 10 & 13 & 11 & 14 & 6 & 9 & 138 \\
\hline 4 & $\begin{array}{l}\text { Pertanian, } \\
\text { Perhutanan } \\
\text { dan Perikanan }\end{array}$ & 35 & 38 & 44 & 31 & 29 & 42 & 42 & 23 & 37 & 37 & 42 & 40 & 440 \\
\hline 5 & Kemudahan & 4 & 5 & 4 & 6 & 7 & 11 & 10 & 9 & 8 & 5 & 4 & 13 & 86 \\
\hline 6 & $\begin{array}{l}\text { Pengangkutan, } \\
\text { Penyimpanan } \\
\text { dan } \\
\text { Komunikasi }\end{array}$ & 8 & 6 & 11 & 6 & 9 & 14 & 16 & 5 & 8 & 7 & 7 & 10 & 107 \\
\hline 7 & $\begin{array}{l}\text { Perdagangan } \\
\text { Borong dan } \\
\text { Runcit }\end{array}$ & 9 & 10 & 7 & 5 & 6 & 8 & 11 & 11 & 14 & 11 & 6 & 4 & 102 \\
\hline 8 & $\begin{array}{l}\text { Hotel dan } \\
\text { Restoran }\end{array}$ & 2 & 3 & 3 & 11 & 8 & 7 & 3 & 5 & 8 & 3 & 7 & 2 & 62 \\
\hline 9 & $\begin{array}{l}\text { Kewangan, } \\
\text { Insuran, } \\
\text { Hartanah dan } \\
\text { Perkhidmatan } \\
\text { Perniagaan }\end{array}$ & 6 & 4 & 6 & 5 & 10 & 8 & 8 & 5 & 11 & 18 & 13 & 11 & 105 \\
\hline 10 & $\begin{array}{l}\text { Perkhidmatan } \\
\text { Awam dan } \\
\text { pihak } \\
\text { Berkuasa } \\
\text { Berkanun }\end{array}$ & 4 & 2 & 2 & 1 & 3 & 1 & 3 & 1 & 1 & 6 & 5 & 2 & 31 \\
\hline & & 263 & 189 & 252 & 226 & 207 & 300 & 309 & 253 & 281 & 290 & 224 & 215 & 3009 \\
\hline
\end{tabular}

Menurut Mazliah \& Abdul Rahman (2012), antara faktor lain yang membawa kepada pengenalan AKKP (1994) adalah disebabkan Akta Kilang dan Jentera 1967 dilihat banyak kelemahan terutama dari aspek keselamatan tempat kerja, dan statistik kemalangan di tempat kerja juga menunjukkan peningkatan setiap hari. Di bawah Akta Kesihatan dan Keselamatan Pekerjaan (AKKP) 1994, majikan merupakan individu yang bertanggungjawab untuk mengambil berat tentang keselamatan dan kesihatan para pekerja ketika bekerja dan juga orang lain yang turut berada di kawasan tersebut.

Justeru itu, salah satu daripada perkara yang dititikberatkan oleh AKKP (1994) adalah untuk meningkatkan kesedaran para majikan dan pekerja di negara ini tentang pentingnya amalan keselamatan dan kesihatan pekerjaan. Tujuan penyelidikan ini adalah untuk menilai amalan keselamatan dan kesihatan pekerjaan di bengkel dalam kalangan pelajar-pelajar jurusan teknikal vokasional di institut latihan vokasional di Malaysia.

Isa, R. F. M. (2019). Technical and Vocational Education and Training (TVET): Tempat Asas Pembinaan Budaya Keselamatan di Malaysia. Journal of Vocational Education Studies, 2(2), 101112. DOI: https://doi.org/10.12928/joves.v2i2.1205. 


\section{TINJAUAN LITERATUR}

Di dalam pendidikan kejuruteraan seperti teknologi mekanikal, elektrik dan elektronik, pelajar dikehendaki menggunakan pelbagai mesin, alatan, perkakas dan bahan di dalam ujikaji makmal ataupun dibengkel semasa kerja amali. Para pelajar perlu mengetahui bagaimana menggunakan alatan dan mesin dengan selamat. Setelah tamat pengajian para pelajar akan menyelia pekerja dan mengajar bagaimana menggunakannya serta mempraktikkan peraturan keselamatan di dalam bengkel di tempat mereka berkerja. Dengan itu, pelajar kejuruteraan ini mesti dididik dan dilatih supaya melengkapkan diri dengan pengetahuan yang cukup tentang keselamatan bengkel dan peraturan bengkel bagi memperolehi kebiasaan dan sikap mementingkan keselamatan (Norizzaidah, 2012).

Pada tahun 1970, Amerika Syarikat telah mewujudkan satu undang-undang dan akta mengenai keselamatan. Akta tersebut dikenali sebagai 'Occupational Safety and Health' atau ringkasnya OSHA. Akta ini diperkenalkan bertujuan untuk menjamin keselamatan dan kesihatan pekerja di bengkel atau industri. Di Malaysia akta keselamatan iaitu PERKESO atau Pertubuhan Keselamatan Sosial telah ditubuhkan pada tahun 1969. Akta ini bertujuan untuk melaksanakan, mentadbir dan menguatkuasakan akta keselamatan sosial pekerja dan peraturan-peraturan keselamatan sosial pekerja (Jabatan Keselamatan dan Kesihatan Pekerjaan, 1994).

Penubuhan akta ini adalah untuk menjamin cara kerja dan juga persekitaran kerja yang selamat kepada para pekerja. Antara akta yang telah ditubuhkan ialah Akta Kilang dan Jentera 1967 yang bertujuan untuk melindungi pekerja daripada bahaya dalam kerja-kerja industri. Ini termasuklah penyakit pekerjaan dan meletakkan piawai minimum persekitaran kerja yang diperlukan untuk keselamatan dan kesihatan. Akta lain yang telah ditubuhkan ialah Akta Keselamatan dan Kesihatan Pekerja 1994 dan banyak lagi. Kesemua akta yang dibuat adalah untuk mencegah kemalangan daripada berlaku (Norizzaidah, 2012).

Bagi memastikan hasrat untuk mengurangkan kadar kemalangan di tempat kerja, kesedaran terhadap keselamatan perlu dijadikan budaya dalam kehidupan pelajar. Oleh itu kesedaran yang tinggi yang dipupuk sejak di bangku sekolah lagi di kalangan pelajar dapat melahirkan pekerja yang berkualiti dan mementingkan keselamatan di bidang pekerjaan (Norizzaidah, 2012).

Untuk memenuhi keperluan sektor industri, pelajar-pelajar akan didedahkan dengan pelbagai bidang kemahiran dan pengetahuan. Pelajar-pelajar ini juga dilatih bagaimana hendak menggunakan peralatan tangan serta pengendalian mesin. Dalam usaha mempelajari dan memenuhi semua kemahiran ini, pelajar bukan sahaja berdepan dengan kemungkinan berlakunya kesilapan dan kegagalan tetapi juga akan menghadapi pelbagai risiko kecuaian dan kemalangan yang boleh berlaku pada bila-bila masa. Kemalangan yang terjadi di dalam bengkel bukan sahaja akan mengakibatkan kerosakan harta benda dan kecederaan anggota badan manusia malah membawa maut (Azhar, 2008).

Kepentingan amalan keselamatan perlu diserapkan dalam diri setiap pelajar supaya wujud kesedaran tentang kepentingan keselamatan. Ini adalah kerana pelajar adalah pelatih yang akan menjalani tugas kerja sebenar di bengkel pada masa akan datang. Oleh sebab itu, adalah perlu pelajar-pelajar diterapkan dengan kesedaran keselamatan semasa menjalani kerja-kerja amali dibengkel supaya mereka membiasakan diri untuk melakukan kerja dalam keadaan yang selamat (Ahmad, 2002).

Kesedaran keselamatan di tempat kerja harus diberi perhatian utama bagi mengurangkan kes kemalangan di samping menjaga kepentingan pekerja jika berlaku kemalangan di tempat kerja. Bahkan tindakan wajar diambil ke atas majikan yang gagal memastikan kebajikan pekerja mereka sentiasa dijaga (Ahmadon, 2006).

Isa, R. F. M. (2019). Technical and Vocational Education and Training (TVET): Tempat Asas Pembinaan Budaya Keselamatan di Malaysia. Journal of Vocational Education Studies, 2(2), 101112. DOI: https://doi.org/10.12928/joves.v2i2.1205. 
Di samping itu organisasi perlu menyediakan polisi keselamatan pekerjaan yang jelas bagi mencegah kemalangan serta mengadakan bengkel keselamatan sebagai usaha untuk meningkatkan kefahaman dan kesedaran keselamatan pekerjaan seterusnya dapat memupuk persekitaran budaya kerja selamat di tempat kerja. Aspek latihan yang penting kepada pekerja iaitu latihan-latihan keselamatan dan kesihatan pekerjaan.

Dengan menyediakan pendidikan dan latihan keselamatan yang efektif, pekerja akan mempelajari bagaimana untuk mengawalnya serta menghindari kemalangan. Jesteru itu, jaminan keselamatan pekerjaan di tempat kerja perlu diberi perhatian khusus kerana kemalangan di tempat kerja akan menjejaskan imej dan reputasi. Budaya kerja selamat perlu diamalkan di tempat kerja bagi mencapai kehidupan bekerja yang bekualiti dan selamat serta mengurangkan rosiko kemalangan di tempat kerja (Misnan, 2011).

\section{METODOLOGI KAJIAN}

Reka bentuk kajian merupakan satu aspek perancangan yang sangat penting. Ia merupakan salah satu tatacara pengolahan data yang dikumpulkan berdasarkan perancangan khusus dan bersistemaik yang melibatkan rangkaian pembolehubah dalam kajian berkenaan Kerlinger (1986).

Dalam kajian ini ia dilaksanakan dalam tiga bahagian iaitu Bahagian A adalah mengenai maklumat diri responden. Bahagian B adalah kajian tinjauan dengan menggunakan soal selidik, soalan terbuka dengan responden pelajar dan pensyarah atau pengajar. Sampel bagi kajian ini terdiri daripada pelajar dan pengajar dari beberapa Institut pendidikan teknik seperti Kolej Vokasional (14 buah), Institut Latihan Perindustrian (10 buah), Institut Kemahiran Belia Negara (10 buah) dan Institut Kemahiran Mara (10 buah). Populasi kajian ini 772 responden terlibat dalam kajian ini. Mereka ini dipilih secara persampelan rawak mengikut kelompak mengikut jantina dan bidang pengkhusas mereka seperti pelajar kejuruteraan mekanikal, kejuruteraan awam dan kejuruteraan elektrik elektronik.

Dalam kajian ini Instrumen kajian dibahagikan kepada dua bahagian A, iaitu bahagian untuk mendapatkan maklumat yang berhubungan diri responden, bahagian $B$ untuk mengukur faktor-faktor yang mempengaruhi amalan keselamatan dan kesihatan pekerjaan, Perlaksanaan keselamatan dan kesihatan pekerjaan, pematuhan keselamatan dan kesihatan pekerjaan, dan budaya keselamatan dan kesihatan pekerjaan.

Menurut Creswell (2010), nilai kebolehpercayaan Cronbach Alpha adalah pengukuran ketekalan dalaman sesuatu konstruk. Alpha yang melebihi 0.60 diguna pakai sebagai indeks kebolehpercayaan sesuatu instrumen (Creswell 2010). Bagi Sekaran \& Bougie (2016), nilai kebolehpercayaan yang kurang daripada 0.60 adalah dianggap rendah dan tidak boleh diterima, nilai Alpha antara 0.60 hingga 0.80 adalah diterima manakala nilai Cronbach Alpha yang melebihi 0.80 adalah dianggap baik. Jadual 3 menunjukkan nilai Cronbach's Alpha bagi amalan, perlaksanaan, pematuhan dan budaya keselamatan.

Jadual 3. Nilai Cronbach Alpha Pembolehubah Kajian

\begin{tabular}{lcc}
\hline \multicolumn{1}{c}{ Pembolehubah } & Bil. Item & Cronbach Alpha \\
\hline Amalan & 10 & 0.79 \\
Perlaksanaan & 10 & 0.75 \\
Pematuhan & 10 & 0.86 \\
Budaya & 23 & 0.84 \\
\hline
\end{tabular}

Isa, R. F. M. (2019). Technical and Vocational Education and Training (TVET): Tempat Asas Pembinaan Budaya Keselamatan di Malaysia. Journal of Vocational Education Studies, 2(2), 101112. DOI: https://doi.org/10.12928/joves.v2i2.1205. 
Merujuk kepada Jadual 3, keseluruhan nilai Cronbach Alpha bagi pembolehubah kajian adalah melebihi nilai 0.70. Ini menunjukkan item-item yang mengukur pembolehubah amalan, perlaksanaan, pematuhan dan budaya adalah sesuai digunakan. Dapatan ini menunjukkan bahawa instrumen yang digunakan mempunyai kebolehpercayaan yang baik.

Soal selidik yang digunakan daripada telah diadaptasi kajian yang dijalankan oleh Durishah Idrus (2004) dalam kajian Tahap Kesedaran Staf UTM terhadap keselamatan dan Kesihatan dan kesihatan di tempat kerja.

Kajian ini melibatkan seramai 772 responden yang terdiri daripada pelajar dan pensyarah empat institut teknikal di Malaysia. Responden lelaki adalah seramai 500 orang $(64.8 \%)$ dan responden perempuan pula adalah seramai 272 orang (35.2\%). Bilangani pelajar dan pensyarah turut menunjukkan komposisi yang sama iaitu 612 pelajar $(79.3 \%)$ dan 160 pensyarah (20.7\%). Tiga kategori umur responden kajian telah dikenal pasti iaitu 17 hingga $26(66.1 \%)$, 27 hingga 34 tahun (6.1\%) dan 35 hingga 55 tahun $(27.8 \%)$. Responden daripada empat institusi teknikal yang terlibat dalam kajian ini ialah 277 orang dari Kolej Vokasional (35.9\%) dan masing-masing seramai 101 orang dari Institut Kemahiran Mara (13.9\%), Institut Latihan Perindustrian (29.7\%) dan Institut Kemahiran Belia Negara (21.4\%). Komposisi responden kajian mengikut bidang menunjukkan seramai 331 orang daripada bidang Kejuruteraan Mekanikal (41.5\%), 169 orang daripada bidang Kejuruteraan Awam (18.3\%) dan 283 orang daripada bidang Kejuruteraan Elekterik Elektronik. Akhir sekali, latar belakang akademik responden kajian mendapati responden dengan kelulusan diploma adalah seramai 154 orang ( $19.9 \%$ ). Sarjana muda seramai 93 $(12.0 \%)$ dan hanya seramai 15 responden memiliki kelulusan sarjana (1.9\%).

Jadual 4. Tahap Amalan, Pelaksanaan, Pematuhan dan Budaya

\begin{tabular}{lllc}
\hline \multicolumn{1}{c}{ Pembolehubah } & & Tahap & Peratusan \\
\hline $\begin{array}{l}\text { Amalan keselamatan dan } \\
\text { kesihatan pekerjaan, }\end{array}$ & Min 3.67 -5.00 & Tinggi & 100 \\
$\begin{array}{l}\text { Perlaksanaan keselamatan } \\
\text { dan kesihatan pekerjaan, }\end{array}$ & Min 3.67-5.00 & Tinggi & 98.3 \\
$\begin{array}{l}\text { Pematuhan keselamatan } \\
\text { dan kesihatan pekerjaan, }\end{array}$ & Min 3.67-5.00 & Tinggi & 98.4 \\
$\begin{array}{l}\text { Budaya keselamatan dan } \\
\text { kesihatan pekerjaan, }\end{array}$ & Min 3.67-5.00 & Tinggi & 100 \\
\hline
\end{tabular}

\section{DAPATAN}

\section{Maklumat deskriptif pembolehubah kajian}

Kajian ini menumpukan kepada satu pembolehubah bersandar iaitu amalan keselamatan dan kesihatan pekerjaan di institut pendidikan teknikal dan vokasional di Malaysia dan tiga pembolehubah bebas iaitu pelaksanaan amalan keselamatan dan kesihatan pekerjaan, pematuhan amalan keselamatan dan kesihatan pekerjaan dan budaya amalan keselamatan dan kesihatan pekerjaan. Jadual 5 menunjukkan nilai min dan sisihan piawai bagi empat pembolehubah kajian.

Isa, R. F. M. (2019). Technical and Vocational Education and Training (TVET): Tempat Asas Pembinaan Budaya Keselamatan di Malaysia. Journal of Vocational Education Studies, 2(2), 101112. DOI: https://doi.org/10.12928/joves.v2i2.1205. 
Jadual 5. Nilai Min dan Sisihan Piawai bagi Amalan, Perlaksanaan, Pematuhan dan Budaya Keselamatan

\begin{tabular}{lcc}
\hline & Min & Sisihan Piawai \\
\hline $\begin{array}{l}\text { Amalan keselamatan dan } \\
\text { kesihatan pekerjaan, }\end{array}$ & 4.63 & .15 \\
$\begin{array}{l}\text { Perlaksanaan keselamatan } \\
\text { dan kesihatan pekerjaan, }\end{array}$ & 4.59 & .23 \\
$\begin{array}{l}\text { Pematuhan keselamatan } \\
\text { dan kesihatan pekerjaan, }\end{array}$ & 4.61 & .25 \\
$\begin{array}{l}\text { Budaya keselamatan dan } \\
\text { kesihatan pekerjaan, }\end{array}$ & 4.61 & .15 \\
\hline
\end{tabular}

Hasil analisis maklum balas pensyarah dan pelajar di institusi teknikal, nilai min dan sisihan piawai, kempat-empat pembolehubah kajian merekodkan adalah seperti berikut; Amalan $(\min =4.63$, sisihan piawai $=0.15)$, Perlaksanaan $(\min =4.59$, sisihan piawai $=$ $0.23)$, Pematuhan $(\min =4.61$, sisihan piawai $=0.25)$ dan Budaya $(\min =4.61$, sisihan piawai $=0.15$ ). Dapatan ini menunjukkan maklum balas respoden terhadap ubah kajian adalah positif dari segi Amalan, Pelaksanaan, Pematuhan dan Budaya.

\section{Dapatan persoalan kajian tahap amalan keselamatan}

Persoalan kajian pertama adalah menjurus kepada tahap amalan keselamatan dan kesihatan pekerjaan di institut pendidikan teknikal dan vokasional di Malaysia. Ianya dikategorikan kepada tiga tahap iaitu tahap rendah, sederhana dan tinggi. Jadual 5 menunjukkan nilai kekerapan dan peratusan tahap amalan keselamatan.

Keseluruhannya, kesemua respoden di institusi teknikal dan vokasional (100\%) menerapkan tahap amalan keselamatan yang tinggi. Dapatan ini menunjukkan bahawa semua respoden memperaktifkan tahap amalan keselamatan dan kesihatan pekerjaan.

\section{Dapatan persoalan kajian tahap perlaksanaan keselamatan}

Persoalan kajian kedua menumpukan kepada tahak perlaksanaan keselamatan berpandukan kepada tiga tahap iaitu rendah, sederhana dan tinggi. Jadual 5. menunjukkan nilai kekerapan dan peratusan tahap perlaksanaan keselamatan.

Bagi tahap perlaksanaan keselamatan di institusi teknikal dan vokasional, dapatan kajian menunjukkan seramai 759 respoden (98.3\%) melaksanakannya pada tahap tinggi dan hanya seramai 13 respoden (1.7\%) melaksanakannya pada tahap sederhana. Ini bermaksud sebahagian besar pensyarah menyatakan Pelaksanaan Keselamatan ini amat penting dan mesti atau menjadi keutamaan bagi menggelakkan sebarang risiko dan kemalangan dari terjadi di institut pendidikan teknikal dan vokasional masing-masing.

\section{Dapatan persoalan kajian tahap pematuhan keselamatan}

Bagi persoalan kajian ketiga, kajian ini memfokuskan kepada tahap pematuhan amalan keselamatan dan kesihatan pekerjaan di Institut Pendidikan Teknikal dan Vokasional di Malaysia yang merujuk kepada tiga tahap iaitu tinggi, sederhana dan rendah. Jadual 5 menunjukkan nilai kekerapan dan peratusan tahap pematuhan keselamatan.

Hasil analisis deskriptif mendapati pematuhan keselamatan dinyatakan pada tahap tinggi dan sederhana. Seramai 760 responden (98.4\%) bersetuju bahawa pematuhan keselamatan berada pada tahap tinggi dan 12 responden (1.6\%) menyatakan pematuhan keselamatan adalah pada tahap sederhana. Ini bermaksud hampir semua pelajar dan

Isa, R. F. M. (2019). Technical and Vocational Education and Training (TVET): Tempat Asas Pembinaan Budaya Keselamatan di Malaysia. Journal of Vocational Education Studies, 2(2), 101112. DOI: https://doi.org/10.12928/joves.v2i2.1205. 
pensyarah bersetuju pematuhan amalan keselamatan dan kesihatan pekerjaan amat penting dipatuhi dan diamalkan oleh setiap pelajar dan pensyarah.

\section{Dapatan persoalan kajian tahap budaya keselamatan}

Persoalan kajian keempat adalah menjurus kepada tahap budaya keselamatan dan kesihatan pekerjaan di Institut Pendidikan Teknikal dan Vokasional di Malaysia Ianya dikategorikan kepada tiga tahap iaitu tahap rendah, sederhana dan tinggi. Jadual 4.6 menunjukkan nilai kekerapan dan peratusan tahap budaya keselamatan.

Keseluruhannya, kesemua responden di institusi teknikal (100\%) menerapkan tahap budaya keselamatan yang tinggi. Dapatan ini menunjukkan bahawa Keseluruhan respoden mengakui bahawa mereka membudayakan keselamatan dalam tugasan harian di bengkel dan tempat kerja.

\section{PERBINCANGAN DAN KESIMPULAN}

Perubahan masa hadapan Malaysia secara keseluruhannya lebih bermula dari kecemerlangan pendidikan (Aminuddin, 2011). Reformasi sistem pedidikan TVET khususnya yang diolah dengan penambahbaikan memenuhi kehendak semasa dan akan datang bakal melahirkan modal insan kelas pertama, mempunyai kemahiran dan kebolehpasaran tinggi.

Melalui Pendidikan Teknikal dan Latihan Vokasional TVET terbukti telah banyak menyumbang kepada melahirkan modal insan berkemahiran yang diperlukan dalam pembangunan Negara untuk menuju status negara maju menjelang 2020. Dengan adanya pendidikan dan latihan yang disediakan oleh institusi TVET, tenaga kerja yang dihasilkan berupaya menjadi tenaga terlatih dan kompeten, serta mempunyai nilai tambah untuk menyumbang secara positif kepada keperluan industri dan pasaran kerja dan mempertingkatkan usaha untuk menghasilkan pekerja yang berpendapatan tinggi (Mohd Jalil, Noor Hisham, Annas, 2015).

Menurut Berita Harian (2019), dunia hari ini juga memperlihatkan kejayaan sesebuah negara bukan saja diukur dan didorong oleh prestasi ekonomi, pembangunan infrastruktur, syarikat multinasional dan teknologi semata-mata, tetapi pembangunan modal insan holistik disandarkan kepada pendidikan, latihan dan kemahiran menjadi sama penting di dalam ukuran kejayaan itu. Pembangunan modal insan menjadi nadi dan penggerak pembentukan masyarakat untuk maju, proaktif dan berinovatif seterusnya berkemampuan menyumbang kepada pembangunan ekonomi dan negara keseluruhannya. Beliau juga menetekankan bahawa pembangunan modal insan amat kritikal bagi masa depan negara. Dengan memartabatkan TVET, kerajaan berkeyakinan negara mampu menghasilkan modal insan berkemahiran yang diperlukan oleh industry.

Berdasarkan dapatan yang dibuat, hampir semua Institut Pendidikan Teknikal dan Latihan Vokasional TVET di Malaysia mengamalkan amalan keselamatan dan dan kesihatan pekerjaan di mana ia merupakan tempat asas pembinaan budaya keselamatan. Pihak pengurusan institut menitikberatkan mengenai risiko bahaya yang boleh berlaku di tempat mereka belajar dan bekerja. Amalan Keselamatan dan Kesihatan pekerjaan. ini juga berfungsi agar pelajar atau pekerja dapat menghindari lebih awal sekiranya perkara yang tidak diduga akan berlaku yang boleh mengancam keselamatan dan kesihatan pekerja.

Dengan adanya Akta Keselamatan dan Kesihatan Pekerjaan 1994 (Akta 514) yang telah dikuatkuasakan sejak tahun 1994 dapat membantu institut Pendidikan Teknikal dan Latihan Vokasional TVET memfokuskan ke arah pembentukan sistem pengurusan keselamatan dan kesihatan pekerjaan. Ia juga dapat menyediakan rangka perundangan untuk memupuk, merangsang dan menggalakkan mutu keselamatan yang tinggi di tempat

Isa, R. F. M. (2019). Technical and Vocational Education and Training (TVET): Tempat Asas Pembinaan Budaya Keselamatan di Malaysia. Journal of Vocational Education Studies, 2(2), 101112. DOI: https://doi.org/10.12928/joves.v2i2.1205. 
kerja dengan meletakkan tanggungjawab tersebut kepada pihak tertentu yang terlibat dalam bidang industri.

Pendekatan komitmen pemimpin dari pihak pengurusan organisasi TVET dapat dilaksanakan sepenuhnya dan berjaya jika mereka bersetuju untuk menyediakan persekitaran kerja yang selamat dan sihat sebagai satu strategi pembaikan prestasi amalan keselamatan dan dan kesihatan pekerjaan.

Menurut Seksyen 16 Akta Keselamatan dan Kesihatan Pekerjaan 1994, setiap tempat kerja atau institut pendidikan teknikal perlu menyediakan dan mengkaji semula penyataan bertulis mengenai dasar berkenaan dengan organisasi serta hal keselamatan dan kesihatan pekerja semasa bekerja di tempat kerja di samping mengemaskinikan semula dasar dan memberitahu pelajar atau pekerja mengenainya amalan keselamatan yang wujud atau perubahan yang berlaku. Atas alasan ini , para profesional keselamatan dan kesihatan moden mesti mampu menjelaskan komitmen kepemimpinan dengan penuh keyakinan.

Antara komitmen penting adalah mengurus aktiviti keselamatan dan kesihatan pekerjaan, kecekapan pengurusan dalam menilai sejauh mana organisasi dapat menyediakan persekitaran yang selamat untuk setiap pekerja di bawah tanggungjawab mereka. Sehubungan dengan perkara tersebut, pembangunan budaya keselamatan di Institut Pendidikan Teknikal dan Latihan Vokasional TVET berupaya meningkatkan kualiti dan imej menrusi elemen-elemen sumber manusia yang ada dalam institut itu sendiri menerusi budaya kerja dengan menjadikan keselamatan sebagai budaya utama dalam pendidikan teknikal TVET (Misnan, 2011).

Cadangan yang boleh dipertimbangkan Kementerian Sumber Manusia dan pihak Kementerian Pendidikan melalui latihan TVET bagi membangunkan budaya keselamatan dalam organisasi antaranya ialah:

(1) Memperbanyakan program latihan untuk semua pelajar dan pekerja yang terlibat dalam industri pembinaan dan pembuatan. Dari kajian didapati pendidikan dan latihan amat penting bagi meningkatkan tahap kesedaran pekerja terhadap keselamatan dan kesihatan. Cadangan ini mampu meningkat kesedaran terhadap keselamatan dan kesihatan serta mendorong mereka untuk mematuhi prosedur pelaksanan amalan kerja selamat. Apabila semua pelajar mengambil bahagian dalam program latihan keselamatan akanmewujudkan kesedaran terhadap keselamatan.

(2) Melaksanakan Sistem Pembangunan budaya keselamatan yang mempertingkatkan amalan tingkah laku keselamatan berterusan bagi mempertingkatkan amalan tingkah laku keselamatan berterusan di kalangan pelajar sepanjang mereka berada di dalam bengkel ketika kerja amali.

(3) Perbanyakan Kempen kesedaran tentang keselamatan. Melalui kempen kesedaran merupakan input tambahan terhadap kepentingan keselamatan dalam bentuk pengetahuan. Organisasi yang kerap menyebarkan dasar dan peraturan keselamatan dan kesihatan pekerjaan akan dapat menimbulkan kepekaan dan kesedaran keselamatan pelajar yang tinggi.

(4) Laksanakan sistem merit kepada pelajar atau pekerja di institut pendikan teknikal dan vokasional.

(5) Mewujudkan sistem pemantauan berkala serta pengawasan dalam pelaksanaan sistem dan standard keselamatan.

(6) Meletakan budaya dan amalan tingkah laku sebagai bahagian utama dalam amalan keselamatan. Budaya keselamatan adalah sebahagian keseluruhan budaya sesebuah organisasi. Pencapaian keselamatan sesebuah organisasi banyak dipengaruhi oleh bahagian pengurusan sesebuah organisasi.

Isa, R. F. M. (2019). Technical and Vocational Education and Training (TVET): Tempat Asas Pembinaan Budaya Keselamatan di Malaysia. Journal of Vocational Education Studies, 2(2), 101112. DOI: https://doi.org/10.12928/joves.v2i2.1205. 
(7) Meningkatkan kepekaan pelajar atau pekerja terhadap keselamatan dan kesihatan dengan melaksanakan insentif satu program yang dapat memotivasikan pekerja dalam sesebuah organisasi.

Budaya Keselamatan bukan sahaja menjadi keutamaan tetapi menjadi budaya dalam masyarakat teknikal dan industri, seteruskan akan menaikankan imej Pendidikan Teknikal dan Latihan Vokasional TVET. dalam meningkat industri yang selamat, berpontensi sebagai kerjaya dan mempunyai imej yang tinggi di kalangan masyarakat.

Dengan terlaksananya amalan keselamatan dan dan kesihatan pekerjaan di institut Pendidikan Teknikal dan Latihan Vokasional TVET dengan baik secara tidak lansung akan terbinalah satu tempat di mana TVET menjadi asas pembinaan budaya keselamatan di Malaysia

\section{RUJUKAN}

Ab. Aziz, Y., \& Intan, O. (2002). Pengurusan Sumber Manusia: Konsep, Isu dan Pelaksanaan. Petaling Jaya: Prentice Hall.

Ahmad, S. (2002) Penghasilan manual keselamatan bengkel kimpalan: Satu tinjauan di Institut Latihan Perindustrian Muar. Thesis. Kolej Universiti Teknologi Tun Hussein Onn.

Ahmadon, B. (2006). Occupational safety and health (OSH) management systems: Towards development of safety and health culture. Proceedings of the 6th Asia-Pacific Structural Engineering and Construction Conference (APSEC 2006), 5-6 September 2006, Kuala Lumpur.

Aminuddin, A. K. (2011). Reformasi dalam TVET: Perubahan masa hadapan. Journal of Edupres, 1, 336-341.

AKKP - Akta Keselamatan dan Kesihatan Pekerjaan. (1994). Peraturan-peraturan Keselamatan dan Kesihatan Pekerjaan. Jawatankuasa Keselamatan dan Kesihatan Malaysia.

Akta Kilang dan Jentera .(1967) - DOSH. Retrieved from: http://www.dosh.gov.my/index.php/ms/perundangan/akta/565-03-akta-kilangdan-jentera.

Azhar, K. (2008). Amalan keselamatan bengkel di kalangan pelajar-pelajar tingkatan 3 aliran Kemahiran Hidup Sekolah Menengah Kebangsaan Tama Conveinct. Retrieved from:

http://www.fp.utm.my/ePusatSumber/pdffail/ptkghdfwP/KHAIRULAP040511 D2008TTP.pdf.

Bahari. (2006). Pengurusan Keselamatan dan Kesihatan Pekerjaan. Kuala Lumpur: McGrawHill.

Bakar, N. A. (2012). Penguasaan amalan keselamatan bengkel di kalangan pelajar kursus Elektrik di salah sebuah kolej komuniti di Negeri Selangor. Dissertation. Universiti Teknologi Malaysia.

Berita Harian. (2019). Persidangan TVET 2019 'Human Capital Development to Enhance Future Skills Agenda' di Putrajaya. Retrieved from: Berita Harian Online.

Charles, A. W. (1998). Safety, Health and Environmental Protection. United States: McGraw Hill Companies.

Creswell, J. W. (2010). Research design: pendekatan kualitatif, kuantitatif, dan mixed. Yogjakarta: PT Pustaka Pelajar.

Isa, R. F. M. (2019). Technical and Vocational Education and Training (TVET): Tempat Asas Pembinaan Budaya Keselamatan di Malaysia. Journal of Vocational Education Studies, 2(2), 101112. DOI: https://doi.org/10.12928/joves.v2i2.1205. 
Haron, H. (2008). Perlaksanaan Akta Keselamatan dan Kesihatan Pekerjaan, 1994 di Institut Latihan Awam. Thesis. Universiti Teknologi Malaysia.

Holt. (2005). Principles of Construction Safety. Oxford: Blackwell Science.

Idrus, D. (2004). Tahap kesedaran staf Universiti Teknologi Malaysia terhadap keselamatan dan kesihatan di tempat kerja. UTM.

Jabatan Keselamatan dan Kesihatan Pekerjaan. (2015). Statistik Kemalangan Pekerjaan Mengikut Sektor sehingga Disember 2015. Retrieved from http://www.dosh.gov.my/index.php/

KPM. (2012). Pelan Pembangunan Pendidikan Malaysia 2013-2025. Putrajaya: Kementerian Pendidikan Malaysia, Putrajaya.

Kementerian Sumber Manusia. (2015). Statistik pekerjaan dan perburuhan. Retrieved from: http://myhos.mohr.gov.my/ebook/istatistik1_2015/bil1_2015.

Mazliah \& Rahman, A. (2012). Tahap Kesedaran Guru-Guru Tadika Terhadap Keselamatan dan Kesihatan Pekerjaan di Tempat Kerja. Retrieved from: http://etd.uum.edu.my/3015/.

Misnan, M. S. (2011). Pembangunan Budaya Keselamatan di Tempat Kerja. Skudai: UTM Press.

Mohd Jalil, A., Noor Hisham, J., \& Annas, A.H. (2015). TEVT di Malaysia: Cabaran dan Harapan. Seminar Kebangsaan Majlis Dekan-Dekan Pendidikan Awam 2015.

Norizzaidah, A. B. (2012). Penguasaan amalan keselamatan bengkel di kalangan pelajar kursus elektrik di salah sebuah kolej komuniti di negeri Selangor. Tesis Ijazah Sarjana Muda Teknologi serta Pendidikan Universiti Teknologi.

Onn, F. C. (2000). Teks Ucapan Pelancaran Kempen Bulan Keselamatan Dan Kesihatan Pekerjaan Pekerjaan. Kuala Lumpur: Kementerian Sumber Manusia.

Rancangan Malaysia. (2010). Rancangan Malaysia Kesepuluh 2011-2015. Putrajaya: Unit Perancang Ekonomi, Jabatan Perdana Menteri.

Roslena, C. J. (2012). Tahap Kesediaan Pelajar kejuruteraan Poleteknik terhadap Keselamatan di Dalam Bengkel. Thesis. Universiti Teknologi Tun Hussein Onn.

Isa, R. F. M. (2019). Technical and Vocational Education and Training (TVET): Tempat Asas Pembinaan Budaya Keselamatan di Malaysia. Journal of Vocational Education Studies, 2(2), 101112. DOI: https://doi.org/10.12928/joves.v2i2.1205. 